\title{
ВЫБОР ОПТИМАЛЬНЫХ УСЛОВИЙ ТЕПЛООТВОДА С БОКОВОЙ ПОВЕРХНОСТИ НЕПРЕРЫВНОЛИТОЙ ЗАГОТОВКИ В ЗОНЕ ВТОРИЧНОГО ОХЛАЖДЕНИЯ
}

\author{
А.С. Нурадинов, Л.Х-А. Саипова, А.Н.Тепсаев
}

Грозненский государственный нефтяной технический университет им. академика М.Д. Миллионщикова, г. Грозный, Россия

Организация технологических мероприятий в зоне вторичного охлаждения (ЗВО) МНЛЗ является крайне важной с точки зрения формирования качества непрерывнолитой заготовки. Процесс формирования заготовки в этой зоне должен исключить формирование различного рода термических внутренних напряжений в твердой корке заготовки. Режимы вторичного охлаждения влияют на геометрию заготовки, формирования трещин, осевой пористости и ликвации $[1,2]$.

В нижней части ЗВО процесс теплоотвода должен быть организован таким образом, чтобы исключить образование трещин и ликвации вблизи фронта затвердевания. Для вытягивания заготовки необходимо создать усилие между роликами и формирующимся слитком таким образом, чтобы уменьшить растягивающие усилия, действующие на его оболочку во время вытягивания.

Охлаждение заготовки в ЗВО происходит за счет опрыскивания еe поверхности водой и отвод тепла к поддерживающим роликам с внутренним охлаждением и за счет конвективного и радиационного теплового обмена с окружающей средой. Установлено, что доля суммарного теплоотвода в ЗВО составляет 75-78\%, причем до 40 \% тепло передается воде, около $30 \%$ поддерживающим роликам с внутренним охлаждением и порядка 8\% происходит потерь за счет конвекции и излучения [3, 4].

Для благоприятного формирования слитка необходимо, чтобы тепловой поток через затвердевшую корку слитка и 
теплоотвод с поверхности были одинаковыми. При недостаточном теплоотводе с боковой поверхности наблюдается повышение температуры затвердевшего металла, уменьшение толщины затвердевшей корочки, ее разогрев и как следствие, снижение еe прочностных характеристик. Последнее может привести к аварийным технологическим последствиям.

В случае теплоотвода с боковой поверхности намного превышающем теплоотвод через затвердевшую корочку наблюдается резкое снижение температуры наружной поверхности. Следствием этого процесса является увеличение температурного градиента в затвердевающей корке, который обуславливает повышенное термонапряженное состояние затвердевшего металла, которое в критических случаях может привести к трещинообразованию на наружной поверхности слитка.

Считается, что оптимальной температурой поверхности в ЗВО охлаждения является температура $1000-1100^{\circ} \mathrm{C}$. Но этот температурный диапазон зависит от ряда факторов, включающих, марку стали, метод охлаждения, тип МНЛ3, характер отвода тепла в ЗВО [5-7].

Протяженность ЗВО выбирается из соображений того, что температура поверхности существенно не меняется (не наблюдается тепловых скачков) после выхода из нее. Увеличение 3ВО, как правило, связано с увеличением скорости разливки и поддержанием заданного диапазона температуры поверхности в нижней части слитка.

Для обеспечения равномерного охлаждения заготовки по длине ЗВО предусматривается использование участков с различной интенсивностью отвода тепла. Необходимая интенсивность теплоотвода обеспечивается за счет применения различных методов подачи охлаждающего вещества. Среди них, как указывалось выше, чаще всего используют струйное и водовоздушное охлаждение. 
Оптимальным условием охлаждения боковой поверхности заготовки в ЗВО является равенство теплового потока подведенного к фронту затвердевания и отведенного с боковой поверхности, т.е. [5]:

$$
-\lambda \frac{\partial T}{\partial x}=\alpha\left(T_{n}-T_{o x}\right)
$$

где $\lambda$ - коэффициент теплопроводности затвердевающего металла; $\alpha$ - эффективный коэффициент теплоотвода с боковой поверхности заготовки; $T_{n}$ - температура наружной поверхности; $T_{o x}$ - температура охлаждающего реагента.

Правая часть (1) соответствует тепловому потоку от центральных областей перегретого металла, проходящему через толщину затвердевшего металла к боковой поверхности заготовки. Поэтому величину этой составляющей можно оценить следующим образом:

$$
-\lambda \frac{\partial T}{\partial x} \approx-\lambda \frac{T_{n}-T_{s}}{\delta}
$$

где $T_{s}$ - температура солидус металла слитка; $\delta$ - толщина затвердевшей корки.

С учетом (2) уравнение (1) примет вид:

$$
-\lambda \frac{T_{n}-T_{s}}{\delta}=\alpha\left(T_{n}-T_{o x}\right) .
$$

Тогда, согласно (3) фактическую интенсивность теплоотвода с боковой поверхности заготовки в ЗВО можно оценить в соответствии с выражением:

$$
\alpha=-\lambda \frac{\left(T_{n}-T_{s}\right)}{\delta\left(T_{n}-T_{o x}\right)} .
$$

При серийном производстве непрерывнолитой заготовки выражение (4) может быть использовано при проектировании ЗВО и выборе оптимальных условий теплоотвода по технологической линии вытягивания. 
Алгоритм оценки интенсивности теплоотвода может быть организован следующим образом. Используя компьютерное моделирование, которое было протестировано как адекватное, рассчитываем толщину затвердевшей корки после выхода заготовки из кристаллизатора. Полученное значение является параметром для оценки интенсивности теплоотвода в зоне ниже кристаллизатора. Таким образом, по расчетной толщине корки на предыдущем уровне (относительно кристаллизатора) рассчитываем коэффициент теплоотвода $\alpha=\alpha(z)$ на последующем уровне.

Ниже приведены результаты компьютерного моделирования реализации предложенного алгоритма. В основу компьютерного моделирования положена технология получения непрерывного слитка в условиях комбината МК «Азовсталь ».

На рисунке 1 показано изменение толщины затвердевшей корки (кривая 1) и интенсивности теплоотвода (кривая 2) вдоль технологической линии вытягивания непрерывнолитой заготовки. Для сравнения на этом же рисунке приведены данные режима охлаждения МК «Азовсталь» (пунктирные кривые). Как видно из приведенных кривых толщина затвердевшей корочки, образованной при технологическом режиме комбината и расчетном режиме, отличается незначительно, однако коэффициент теплообмена, по предлагаемому режиму охлаждения $(\alpha=\alpha(\delta))$, изменяется более плавно.

Сравнивая положение изотерм солидус и ликвидус для обоих вариантов (рис.2) можно отметить, что глубина жидкой лунки сократилась и составила 5,5 м против 5,75 м для базового варианта. Размер твердожидкой фазы увеличился до 9,42м против 9 м. Таким образом, размер двухфазной зоны составляет 3,9 м (против 3,3 м в базовом варианте). 


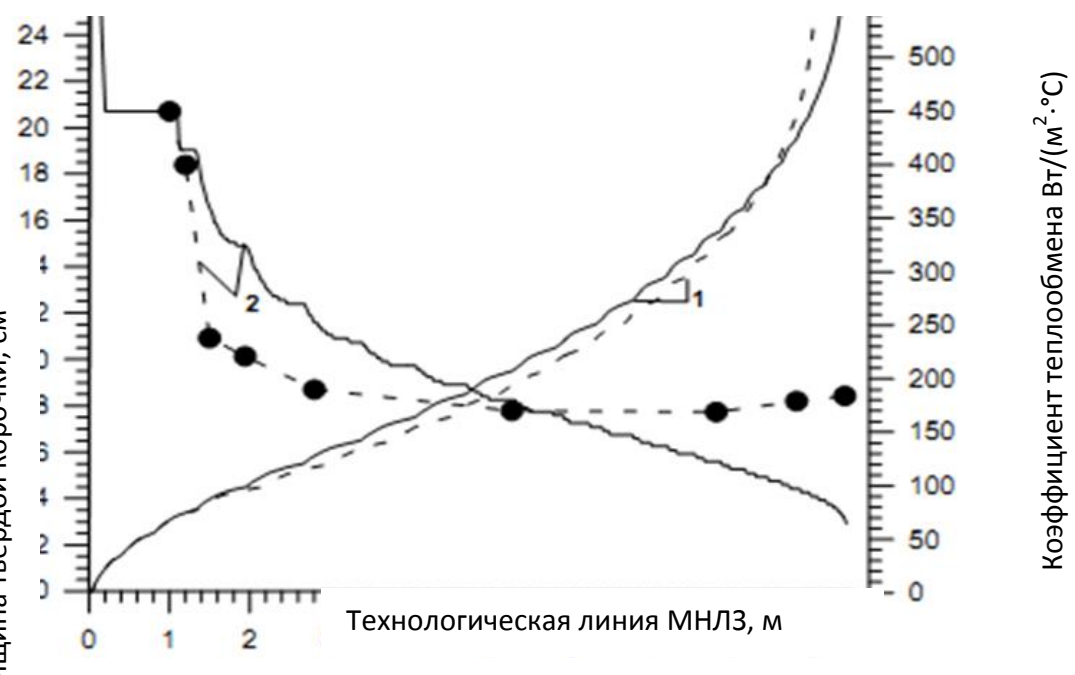

Рис. 1. теплоотдачи (2) с боковой поверхности непрерывнолитой заготовки по технологической линии МНЛЗ: - - режим охлаждения в ЗВО МК «Азовсталь» $(\alpha=\alpha(\mathrm{z}))$; ---- - режим охлаждения в ЗВО выбирается как функция от толщины затвердевшей корочки $(\alpha=\alpha(\delta))$

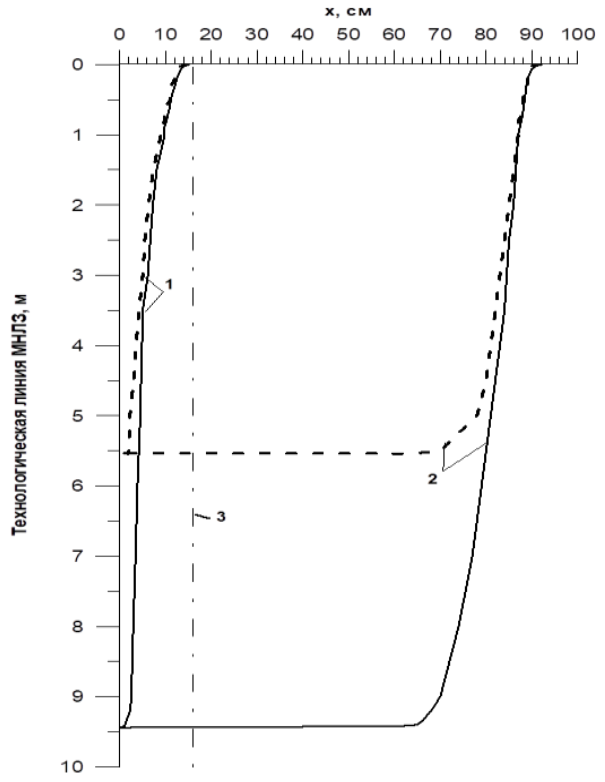

Рис. 2. Положение изотерм солидус (-) и ликвидус (---) по узкой (1) и широкой (2) граням по технологической линии МНЛЗ при затвердевании непрерывнолитой заготовки (3 - размер узкой грани). Режим охлаждения в ЗВО выбирается как функция от толщины затвердевшей корочки $(\alpha=\alpha(\delta))$ 
В процессе охлаждения температура наружной поверхности (рис. 3) изменяется от температуры заливки $1540^{\circ} \mathrm{C}$ до $950{ }^{0} \mathrm{C}$ при выходе из кристаллизатора. Предлагаемый алгоритм изменения интенсивности теплоотвода в зоне вторичного охлаждения обеспечивает плавное снижение температуры боковой поверхности заготовки после выхода ее из кристаллизатора (рис. 3, кр. 1). При базовом режиме охлаждения (рис. 3, кр. 2) после выхода заготовки из кристаллизатора температура повышается до $1100^{\circ} \mathrm{C}$ (на расстоянии 1 метра от кристаллизатора), затем температура наружной поверхности монотонно снижается.

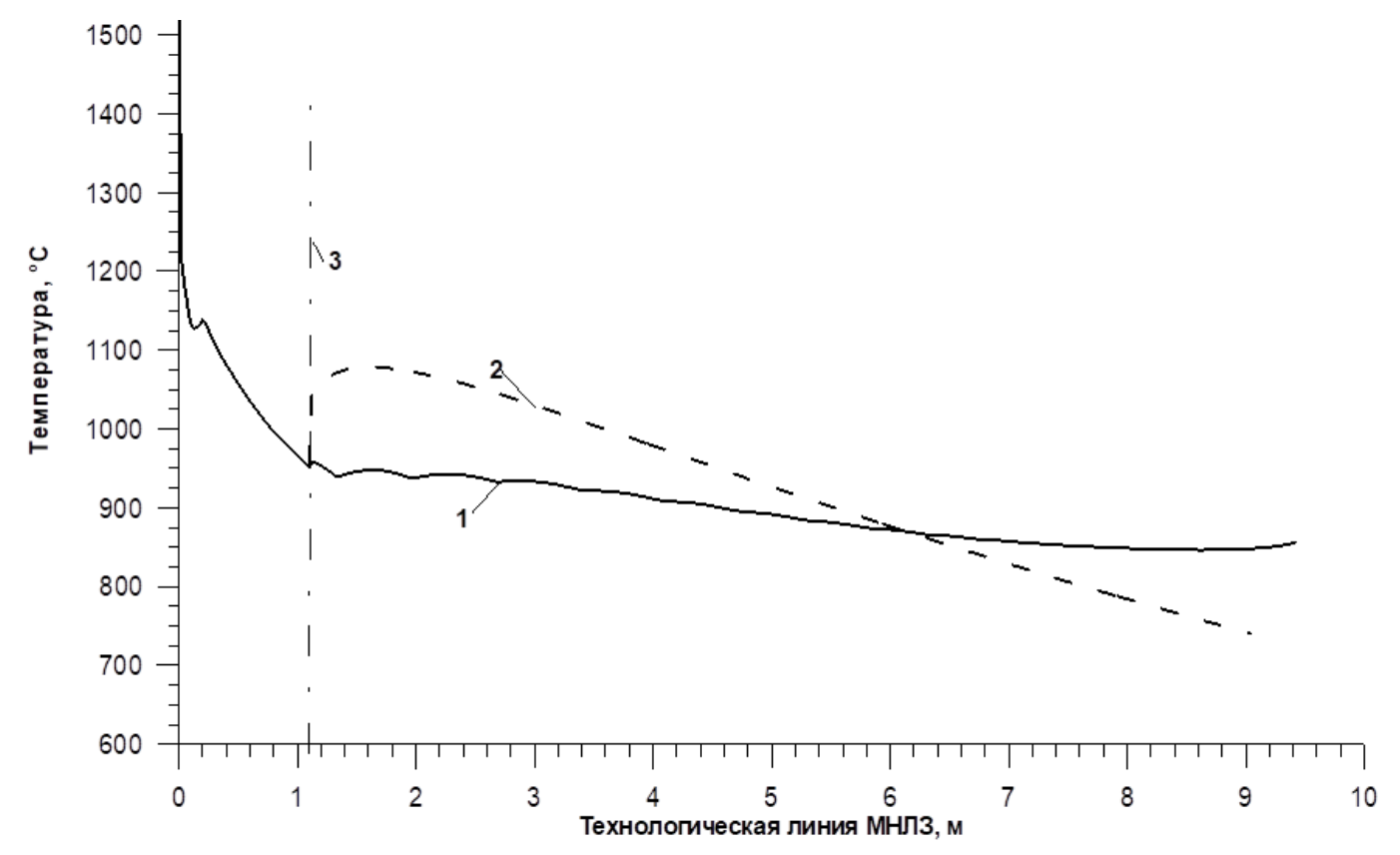

Рис. 3. Изменение температуры поверхности по середине широкой грани непрерывнолитой заготовки вдоль технологической линии МНЛЗ:

1 -режим охлаждения в 3ВО, при котором $\alpha=\alpha(\delta) ; 2$ - базовый вариант режима охлаждения $(\alpha=\alpha(\mathrm{z}))$; 3 - выход из кристаллизатора

На основании изменения температуры поверхности вдоль линии вытягивания и соответствующей толщины корки была 
проведена оценка изменения допускаемых предела прочности и деформации, которые исключают нежелательные изменения напряженно-деформационного состоянии слитка (рис. 4). Как следует из представленных кривых, максимальные значения допустимых характеристик наблюдаем на расстоянии 0.5-1.0 м от кристаллизатора. После выхода из кристаллизатора снижение допустимый предел прочности резко снижается и ниже 8,0 м от мениска устанавливается на одном уровне. Резкое снижение допустимых деформаций наблюдаем на аналогичном участке (до 8,0 м). После указанного участка имеет место незначительное снижение допустимых деформаций вдоль линии вытягивания.

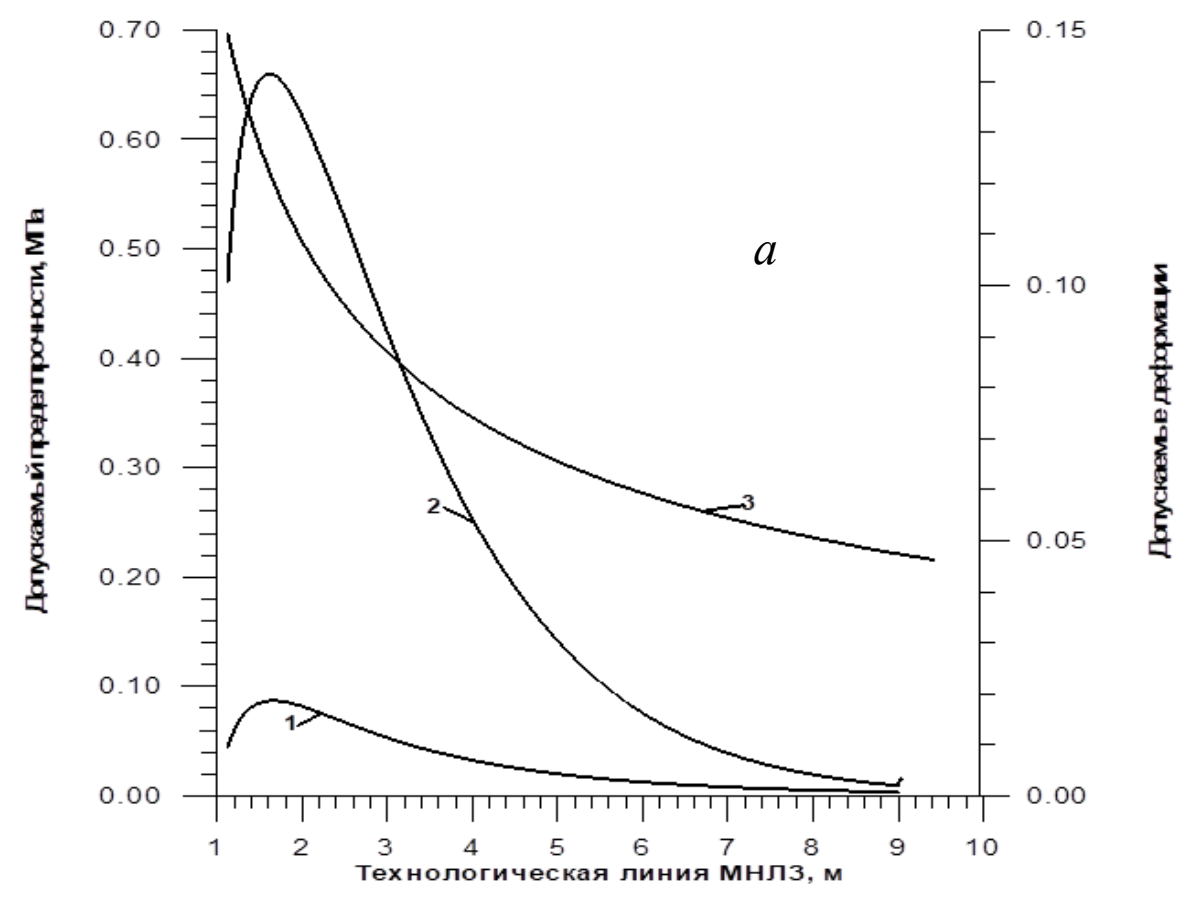




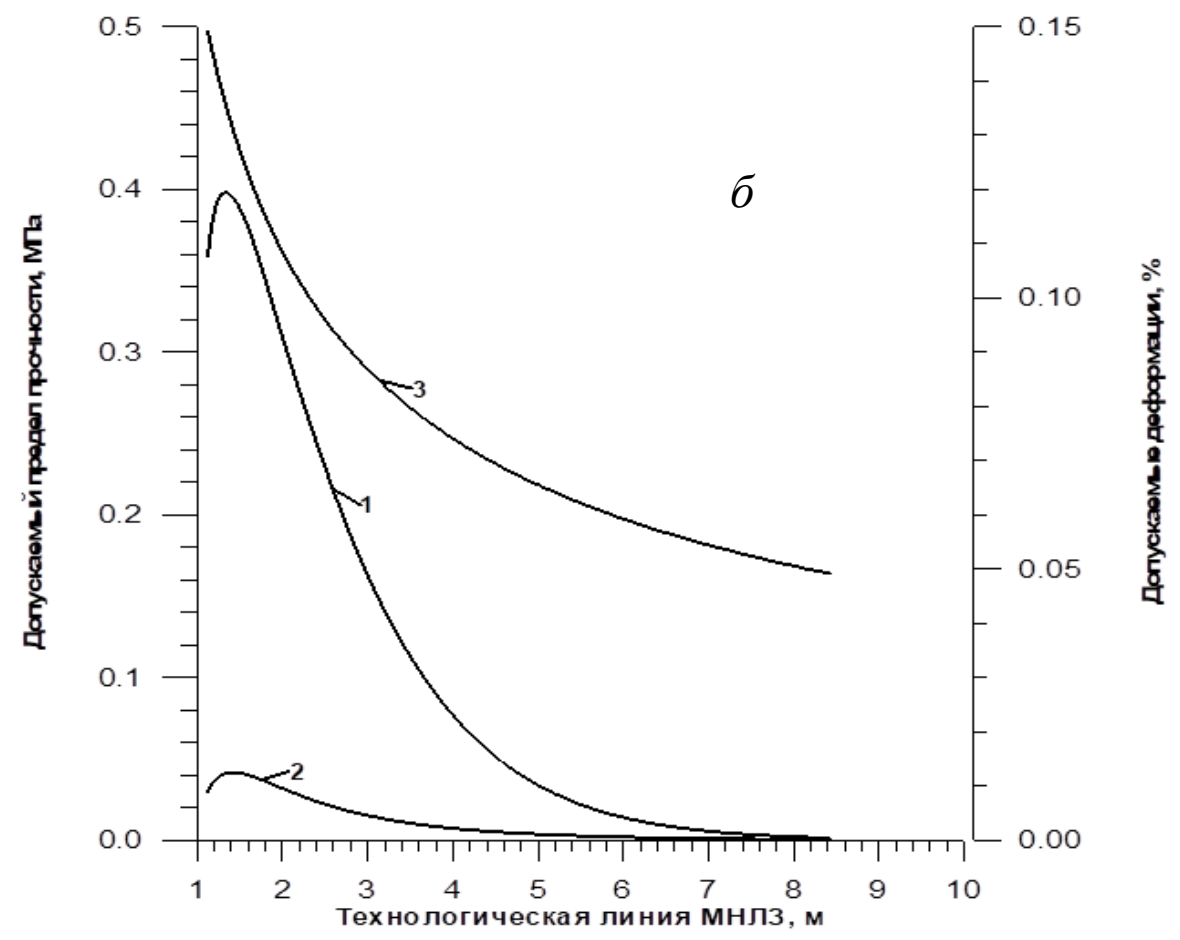

Рис. 4. Изменение допускаемых напряжений $(1,2)$ и деформаций

(3) при различных режимах охлаждения в 3ВО: $a$-базовый вариант; $\sigma$ - измененный вариант

Обращаем внимание на тот факт, что эти характеристики инвариантны относительно проведенных изменений интенсивности теплоотвода в 3ВО (рис.4, б).

Таким образом, наглядно показано, что использование предложенной методики исключило повторный разогрев боковой поверхности заготовки после ее выхода из кристаллизатора, допустимые предел прочности и предел деформации вдоль линии вытягивания инвариантны условиям теплоотвода в ЗВО. По указанному алгоритму может быть проведена оценка интенсивности теплообмена в области зоны вторичного охлаждения, которая обеспечивает оптимальные условия формирования непрерывнолитой заготовки и снижает вероятность появления условий способствующих появлению 
наружных трещин и дефектов, обусловленных повышенным термонапряженным состоянием.

\section{Литература}

1. Смирнов А.Н., Пилюшенко В.Л., Минаев А.А. и др. Процессы непрерывной разливки - Донецк: ДонНТУ, 2002. - 536 с.

2. Смирнов А.Н., Глазков А.Я., Пилюшенко В.Л. и др. Теория и практика непрерывного литья заготовок - Донецк: ДонГТУ, 2000. - 371 с.

3. Лякишев Н.П., Шалимов А.Г. Развитие технологии непрерывной разливки стали. - М.: ЭЛИЗ, 2002. - 208 с.

4. Ефимов В.А., Эльдарханов А.С. Современные технологии разливки и кристаллизации сплавов - М.: Машиностроение, 1998. - 360 с.

5. Буланов Л.В., Корзунин Л.Г., Парфенов Е.П. и др. Машины непрерывного литья заготовок. Теория и расчет / Под ред. Г.А. Шалаева. Екатеринбург: Уральский центр рекламы «Марат», 2004. - 320 с.

6. Буланов JI.B., Юровский Н.А., Парфенов Е.П. Системы динамического регулирования вторичного охлаждения и мягкого обжатия непрерывнолитых заготовок в проектных разработках ООО «УралмашМетоборудование» // Сб. Неделя металлов в Москве. - 2005. - С. 172-180.

7. Паршин В.М., Буланов Л.В. Непрерывная разливка стали. - Липецк: ОАО «JIMK». - 2011. - $221 \mathrm{c}$. 